\title{
Comparison of Defects in Hydride Vapor Phase Epitaxy-Grown GaN Films under Different V/III Ratios and the Influence on the Electrical and Optical Properties
}

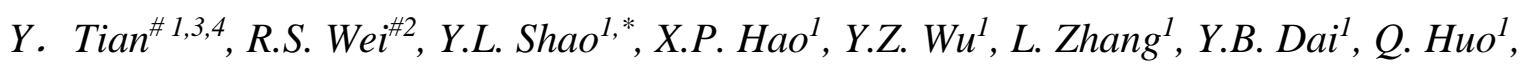 \\ B.G. Zhang ${ }^{l}$, H.X. $H u^{l}$ \\ ${ }^{1}$ State Key Lab of Crystal Materials, Shandong University, Jinan, 250100, PR China \\ ${ }^{2}$ Shanxi Semicore Crystal Co., Ltd., Taiyuan, 030024, PR China \\ ${ }^{3}$ Key Lab of Advanced Transducers and Intelligent Control System, Ministry of Education and Shanxi \\ Province, Taiyuan University of Technology, Taiyuan, 030024, PR China \\ ${ }^{4}$ College of Physics and Optoelectronics, Taiyuan University of Technology, Taiyuan, 030024, PR \\ China \\ *E-mail: ylshao@sdu.edu.cn \\ ${ }^{\#}$ Y. Tian and R.S. Wei are co-first authors of the article.
}

doi: $10.20964 / 2020.12 .33$

Received: 4 August 2020 / Accepted: 22 September 2020 / Published: 31 October 2020

In this paper, GaN films were grown by hydride vapor phase epitaxy under different ratios of $\mathrm{NH}_{3}$ to $\mathrm{GaCl}$ (V/III ratio). Secondary ion mass spectrometry measurements of [Si], [O], [C] and [H] were carried out to analyse the changes in impurities. Molten $\mathrm{KOH}-\mathrm{NaOH}$ eutectic etching was applied to reveal changes in the dislocation density. With increasing V/III ratio, $[\mathrm{O}]$ and the dislocation density decrease, while [Si] increases. Further the influence of the V/III ratio on the electrical and optical properties was examined by Hall and photoluminescence measurements.

Keywords: GaN, Defects, V/III Ratios, Electrical properties, Optical properties

\section{FULL TEXT}

(C) 2020 The Authors. Published by ESG (www.electrochemsci.org). This article is an open access article distributed under the terms and conditions of the Creative Commons Attribution license (http://creativecommons.org/licenses/by/4.0/). 